\title{
Protection of settlements from floods and debris flow on the example of tragedy in Tbilisi on 13-14 June of 2015
}

\author{
Robert Diakonidze, Tamriko Supatashvili, Bela Diakonidze \\ Georgian Technical University, Tsotne Mirtskhulava Water Management Institute, 77 Kostava, Tbilisi, Georgia, e-mail: \\ robertdia@mail.ru,tamunasupatashvili@gmail.com,bella_diakonidze@mail.ru
}

Levan Ioseliani, Ani Getiashvili

Ivane Javakhishvili Tbilisi State University, Ministry of Environment and Natural Recourses Protection of Georgia, 1 Chavchavadze Avenue, Tbilisi 0179, Georgia,e-mail: ioselianilevan@gmail.com,anniegetiashvili@gmail.com

\section{Zurab Laoshvili}

Ivane Javakhishvili Tbilisi State University, 1 Chavchavadze Avenue, Tbilisi 0179, Georgia, e-mail: laoshvili@yahoo.com

\begin{abstract}
This article presents material about the flood on the Vere River on 13-14 June, 2015. It caused significant economic and ecological damage to the country, and there were also human victims. The reasons for the ecological disaster are evaluated and appropriate hydrological calculations have been carried out. It has been particularly established that the predictable (forecasting) maximal discharges of $0,1 \%$ value for Vere River is $520 \mathrm{~m}^{3} / \mathrm{sec}$ and not $410 \mathrm{~m}^{3} / \mathrm{sec}$, that was calculated water conduct tunnels in the entrance of city before the Mtkvari River.

The flood on the 13-14 June 2015 and the connected tragedy was caused by high intensive precipitation in the catchment basin, the activation of geodynamic processes, and also anthropogenic factors. In our opinion, a reason of disaster also was a design flaw in hydrotechnical buildings (tunnels) - they are not able to manage a water flow rate of $0,1 \%$ assurance.

The paper presents the recommendations necessary for us to avoid, or at least reduce, the ecological and economic problems caused by floods and debris flow. The presented recommendations against a disaster like that which affected Tbilisi, as well as the expected environmental problems on territory with similar natural conditions, will enable us to avoid or reduce damage caused by flood and debris flow.
\end{abstract}

Key words: disaster, flood, water discharge, debris flow, landslide

Submitted 22 February 2016, revised 30 May 2016, accepted 4 May 2017

\section{Introduction}

Mankind experiences its greatest economic losses annually through natural disasters, among them floods and debris flows. There are cases of victims. In recent years, the number of natural disasters has increased, and this is related to the planet's climate changes. In addition to this, anthropogenic factors also often become causes of ecological disasters.

A good example of the above is the flood occurred on the Vere River, in the city Tbilisi, on 13-14 June, 2015, where 19 people died and significant economic damage occurred to the country. This was caused by a whole range of factors.

\section{Materials and methodologies}

The aim of the research is to determine reasons of disasters caused by flood; to calculate maximal discharges of $1 \%$ and $0,1 \%$ values; to suggest measures for similar natural disasters, protection or a reduction of the severity of the results of a disaster in an urban area (using the example of Tbilisi).

In this work we will try to describe and evaluate the causes of the above-mentioned tragedy. This will enable us to protect similar areas from disasters and consequently avoid human casualties. For this purpose we have studied the causes of floods and planned necessary measures to avoid such disasters. In the framework of the study a physical map of the river Vere basin and is presented (Fig. 1) and relevant studies for calculating various hydrological and morphometric characteristics necessary to evaluate the tragedy have been conducted. For this the special programmer Arc GIS 10.2.2 was used, field expedition results and photographic materials.

As the result of conducted works (Diakonidze at al. 2015 ) it has been specified: that the Vere River originates 


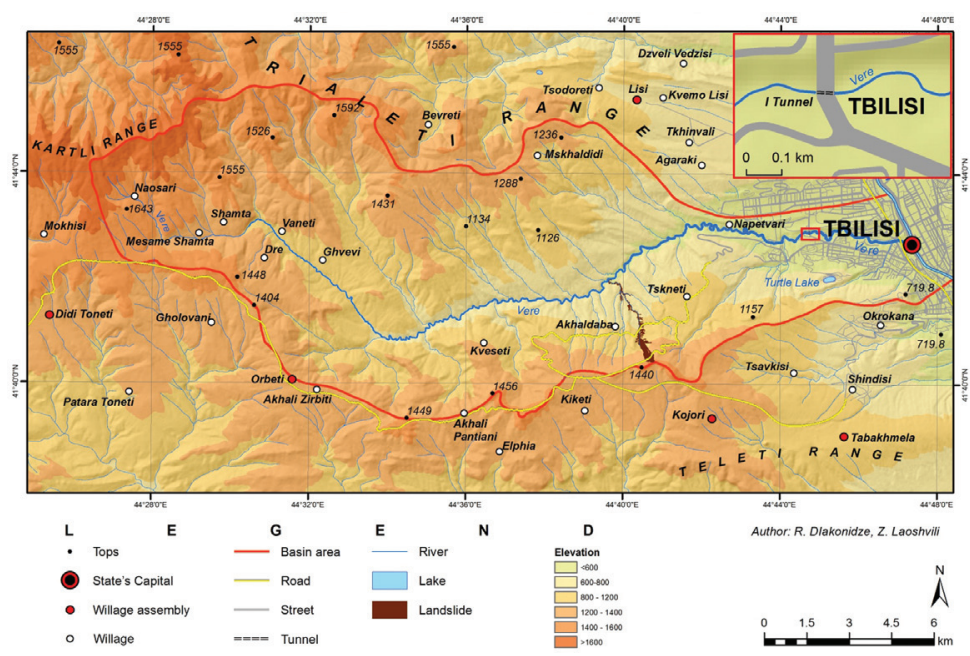

Fig. 1. Physical map of the Vere River basin

from the south-east slope of the Trialeti Range, adjecent to the village of Naosar, 1670 metres above sea level, and joins the right bank of the Mtkvari River 0,5 $\mathrm{km}$ from the bridge at Cheluskine, 394 meters above sea level. The average height of the catchment is $1070 \mathrm{~m}$; the catchment area of the Vere River is equal to $197 \mathrm{~km}^{2}$; the length of the river is $40,1 \mathrm{~km}$. Some tributaries of the river are $10 \mathrm{~km}$; the hydrological network (the rivers considered in the report) total 117,2 kilometers. The average width of the basin is $6,16 \mathrm{~km}$ and a its maximum width is $10,5 \mathrm{~km}$. The calculation of characteristic does not take into account some small size water flow, the influence of which is significant on the river's hydrological regime.

According to works in Georgian hydrological science (Resources of... 1969; Svanidze et al. 1987), multiannual average water flow is $0,98 \mathrm{~m}^{3} / \mathrm{s}$, and $1 \%$ of the maximum water flow rate is $240 \mathrm{~m}^{3} / \mathrm{sec}$. It should be noted that, despite observation on the Vere River over 53 years, the largest amount of recorded water was reported in 1960 a maximum of $259 \mathrm{~m}^{3} / \mathrm{s}$, a figure that differs greatly from the report made on June 13-14, 2015, according to which the average volume of water flow rate was $468 \mathrm{~m}^{3} / \mathrm{sec}$, as calculated by the Ministry of Environmental and Natural Resources.

In our opinion, this is due to the planet's climate change over recent years; the increase in air temperature, often leads to high-intensity rainfall (unfortunately, in the research region there is no device for measuring precipitation). Accordingly to our theoretical calculation, made by using methods tested in hydrological science (Rostomov 1980), it was finally estimated that the predictive water flow rate of $1 \%$ assurance (assurance for 100 years of water flow) of the Vere River is equal $376 \mathrm{~m}^{3} / \mathrm{sec}$, and $0,1 \%$ assurance (assurance for 1000 years of water flow) - is $520 \mathrm{~m}^{3} / \mathrm{sec}$.

\section{Study area}

The Vere River catchment basin is distinguished by its specific geological, geomorphological and morphometric conditions. Though the flood was caused by the rushing of high intensity rainfall in the catchment basin, the sensitive and dangerous geodynamic processes developed on the right slope of the Vere River (in the Akhaladba River basin) also cannot be ignored, and this had a certain impact on the disaster caused by the flood. The connecting road between the borough of Tskneti and the village of Akhaldaba is distinguished by special sensitivity; this is one more reason for unsustainability of the slopes. It would possibly be better if the road elevation was lower. Moreover, in this location there are many rocky developments - Paleozoic sandstone and thin layers of mudstone. Layers of this rock are distributed down the slope, and this causes a high risk of landslides. The sandstone is fractured and it sometimes collapses; due to this, atmospheric precipitations easily gets into the depth of the rock. Water masses leaking in the layers of mudstone create landslide danger zones. After

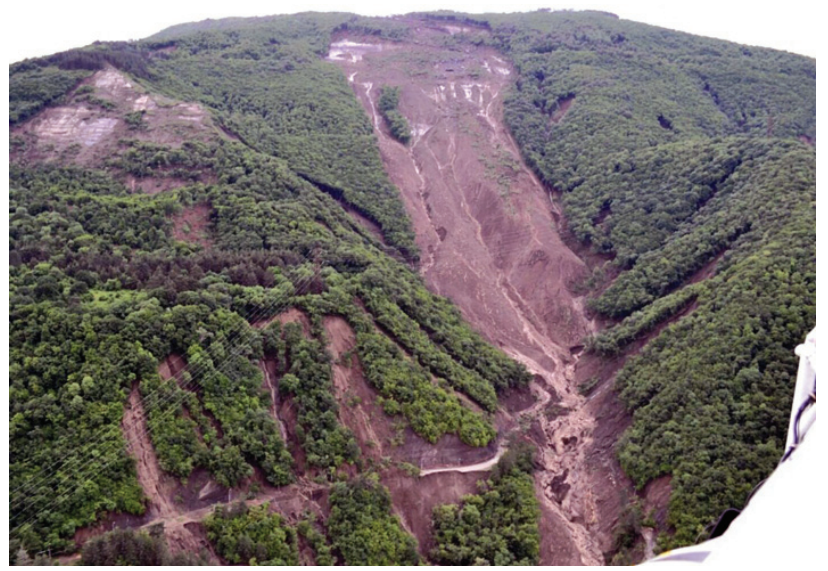

Fig. 2. General view of a landslide formed on the vulnerable slope of the Jokhoniskkhevi River, right tributary of the Vere River (photography by Robert Diakonidze) 
the formation of a landslide on the vulnerable slope of the Jokhoniskhevi River, temporary outlets of infiltrated water present on the slope surface are clearly visible (see Fig. 2).

In our opinion, one of the reasons for the landslide development in the Akhaldabiskhevi and Jokhaniskhevi Rivers (there are many potential landslide centers in the region), in addition to many other factors, is the motorway, clearly a manmade structure. The mass of landslide and debris flow amounted to approximately 1 million $\mathrm{m}^{3}$.

It has been established that the flood in the Vere River was caused by high intensity precipitation that rushed into the valley (the exact amount here is undetermined), producing the landslide, which later bcame a mudslide, bringing down a large amount of wood and solid sediment into the Vere River. All this has reduced the water penetration capacity of the bed of the Vere River. It is though that the debris flow dammed up the bed of the Vere River in a very short time (1-2 min), however, this is only speculation.

Among other factors, this was provoked by the motor way, which is undoubtedly a human creation. The landslide and mud flow had a mass volume of about 1 million $\mathrm{m}^{3}$.

It is already known that the Vere River, after flooding in Tbilisi territory, first rushed through the bridge-tunnel (length $126 \mathrm{~m}$ ) that connects two neighbouring districts (Vake and Saburtalo), and then, before joining the Mtkvari River, it flew into a closed water tunnel. The distance from the confluence to the first bridge-tunnel is $4,8 \mathrm{~km}$. The water permeability of the first bridge-tunnel, according materials in the project framework, is intended for $460 \mathrm{~m}^{3} / \mathrm{sec}$ water transfer, and the closed tunnel located after the above tunnels is intended for $410 \mathrm{~m}^{3} / \mathrm{sec}$ (Kereselidze et al. 2015).

As mentioned above, it has been estimated by Environment Monitoring Department of the Ministry of Environment and Natural Recourses Protection of Georgia that the established water flow rate in the Tbilisi entrance prior to the first tunnel (the village of Naphetvrebi) amounted to

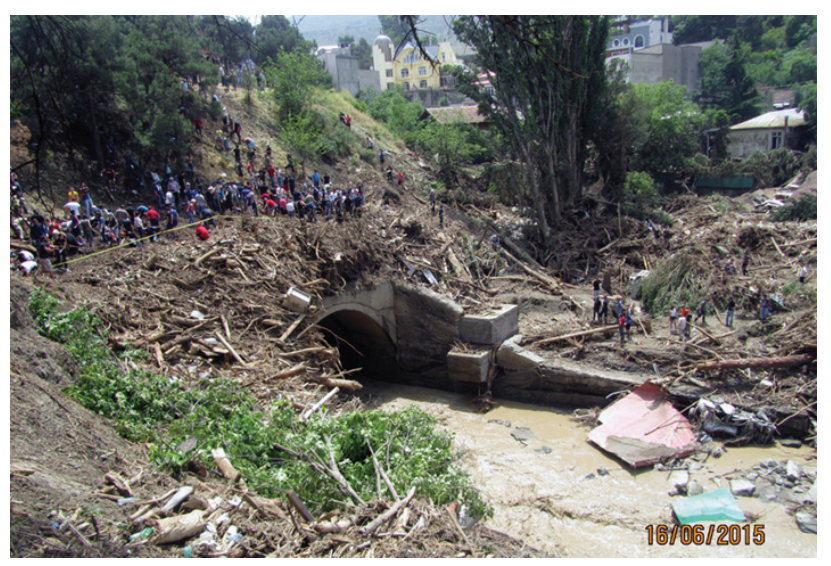

Fig. 3. Oval tunnel positioned under the Vake-Saburtalo motorway and the place of flooding (photography by Robert Diakonidze)
$468 \mathrm{~m}^{3} / \mathrm{sec}$ during the flood. However, it should be noted, that between the water flow measurement point and the point of confluence to the Mtkvari River, there is one tributary of the Vere River - the Bagebistskali; i.e. the water flow rate of the Vere River at the first tunnel was above the water flow rate connected to village of Naphetvrebi as a result of the effect of the Bagebistskali River. After this, the water flow rate reached $500 \mathrm{~m}^{3} / \mathrm{sec}$ that is in excess of the water capacity of the tunnels.

Taking into account the wood brought by Vere River and other anthropogenic factors, it will be clear that the tunnels could not cope with the water flow rate of the Vere River, and, as a result a $600000 \mathrm{~m}^{3}$ capacity artificial reservoir was formed near to the first tunnel (Fig. 1); this is indicated with a red rectangle on the map (the first tunnel is also presented on the map as an insert), (Fig. 3; Kereselidze et al. 2015); this finally broke the new water tunnel positioned after the first tunnel (Fig. 4, 5) and caused the disaster, which resulted in victims. It turns out that the cause of the tragedy, along with a number of other factors, was the neglecting of the requirements necessary for first class building, and particularly, that the tunnels were not intended for a water flow rate $0,1 \%$ assurance.

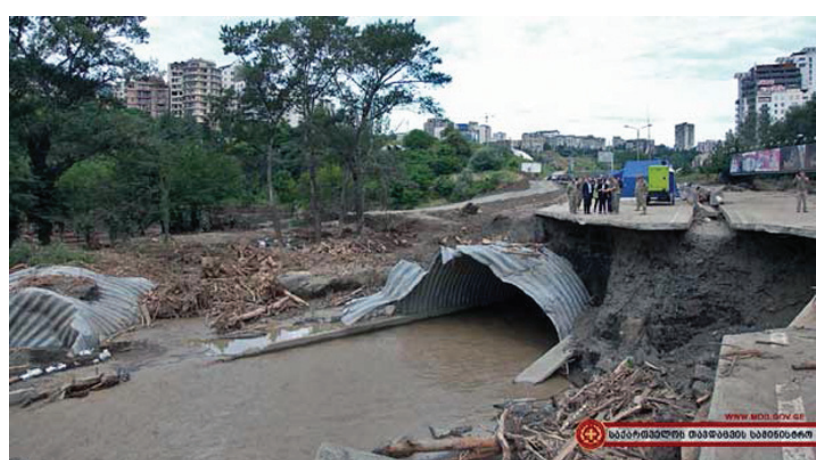

Fig. 4. Newly built tunnel broken by water flow (photography by Robert Diakonidze)

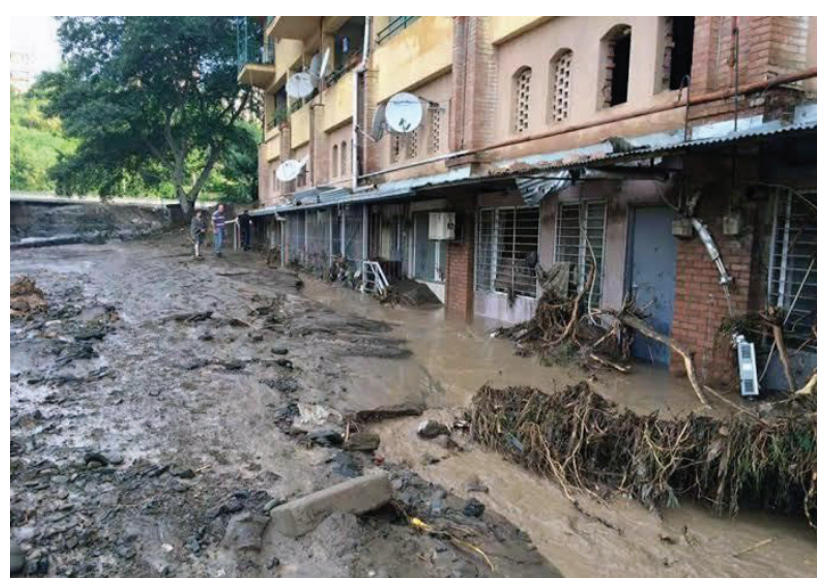

Fig. 5. Flooded settlement territory as a result of broken newly built tunnel (photography by Robert Diakonidze) 


\section{Conclusion}

Analysis of above mentioned information allows us to make the following conclusions (ideally, all necessary data relating to inhabited areas in future will be presented in geoinformation systems, which will allow us to take timely and appropriate action on impending natural disasters by using special methodology and computer programmes):

- The flood on 13-14 June 2015 and the resulting tragedy was caused by a high intensity of rainfall into the catchment basin, the activation of geodynamic processes and anthropogenic factors;

- In our opinion, another reason for disaster was the mistake made in the design of hydrotechnical constructions (tunnels), as they could not transfer the theoretically calculated water flow rate of $0,1 \%$ assurance.

We hereby present the necessary recommendations, which will enable us to avoid, or at least reduce the ecological and economic problems caused by floods and debris flow:

- In urban settlements it is in inappropriate to build a closed type of water permeable construction (in this case - tunnels); if it is necessary to build such constructions due to specific geographical conditions, the strict requirements of first class construction should be considered.

- Illegal constructions in river beds should be prohibited to minimise the anthropogenic influence.

- We should try our best to avoid artificial provocation of sensitive areas from a geodynamic point view.

- Riverbed and coastal protection facilities should be built in order to prevent water outpour from beds during floods or upon damming the beds.

- It is necessary to implement monitoring of the basins of sensitive rivers near settlements in order to determine the values of various hydro meteorological characteristics for the calculation of forecasting values of flood and debris flow.

- To avoiding such tragedies as occurred in Tbilisi and to protect similar geographical environments from floods and mud flow we recommend installing a lattice-like structure to serve as a sediment trap; the first prototype of this was developed in the Georgian Scientific Research Institute of Hydraulic Engineering and Reclamation (now the Tsotne Mirtskhulava Water Management Institute of the Georgian Technical University), and has been developed into its modern version by the Swiss firm Geobrug (Fig. 6).

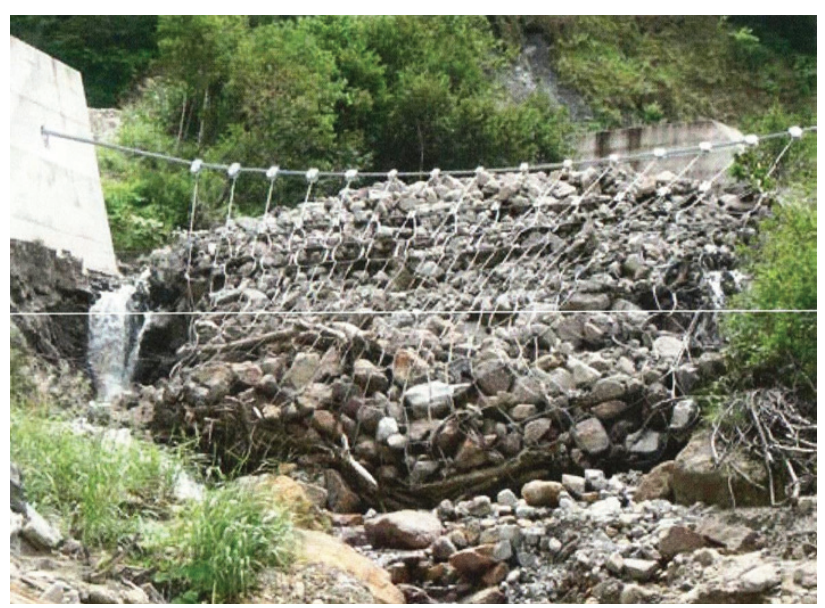

Fig. 6. Construction of lattice type metal networked sediment trap

The proposed premise has many positive aspects: it will save eesources, offer high performance and multiple operational ability.

- It is necessary to develop complete methodology for the calculation of forecasting values of floods and debris flows.

- It is desirable to provide the geoinformational systems of residential areas with all necessary data; this will allow us to take timely and appropriate measures against impending natural disasters by using special methodology and computer programmes.

\section{Bibliography}

Diakonidze R., Panchulidze J., Charbadze Z., Laoshvili Z., Diakonidze B., Kvizhinadze S., 2015, Protection of city Tbilisi from predictable natural disasters on the example of the river Vere, [in:] Proceeding of Tsotne Mirtskhulava Water Management Institute of Georgian Technical University, Tbilisi, $70,50-554$

Kereselidze D., Alaverdashvili M., Tsinstadze T., Trapaidze V., Bregvadze G., 2015, What happened on 13 June 2015 in the catchment basin of the river Vere, Tbilisi, $40 \mathrm{pp}$.

Resources of surface water of the USSR, 1969, vol. 9. Transcaucasia and Daghestan, issue 1. Western Transcaucasia, G.N. Khmaladze (ed.), Gidromet, Izd, Leningrad, 310 pp.

Rostomov G.D., 1980, Technical instructions for the calculation of maximum river runoff in conditions of the Caucasus, Tbilisi, UGKS, 71 pp.

Svanidze G.G., Gagua V.P., Sukhishvili E.V. 1987, Renewable energy resources of Georgia, Leningrad, Hydro metiozdat, 173 pp. 